\title{
Autopsy review of sudden natural death cases at rural government medical college in Maharashtra
}

\author{
Haridas S. V ${ }^{1, *}$, Raut S. M. ${ }^{2}$, Kachare R.V. ${ }^{3}$, Pawar V.G. ${ }^{4}$, Dode P.S. ${ }^{5}$ \\ 1,5Assistant Professor, ${ }^{2}$ Junior Resident, ${ }^{3}$ Professor, ${ }^{4}$ Associate, Dept. of Forensic Medicine, Swami Ramanand Teerth Rural \\ Government Medical College and Hospital, Dist. Beed, Maharashtra, India
}

*Corresponding Author:

Email: sandeepvharidas@gmail.com

\begin{abstract}
Introduction: Sudden deaths in apparently healthy persons might raise doubt of foul play. Hence medico-legal autopsy in such cases is needed to satisfy the aggrieved relatives and it also gives a systemic view of various causes of deaths in such cases which ultimately improve mortality statistics.

Material and Methods: Retrospective analysis of sudden natural death cases which were brought for medico-legal autopsy at Rural Govt. Medical College \& Hospital during the three year period was studied. The data was compiled, tabulated and analyzed statistically.

Results: The incidence of sudden natural death is $16.01 \%$. Most common age group involved was 41-50 years followed by $31-40$ years. Male predominance $(77.42 \%$ ) was noted. Most commonly affected system was cardiovascular system (53\%) followed by respiratory system (33.64\%). Among the cardiovascular system causes Coronary artery disease was accounted in $88.7 \%$ of cases. Among the respiratory system causes pneumonia was predominant with $50.69 \%$ cases.

Conclusion: The incidence of sudden natural death is $16.01 \%$. Males having age 41-50 years are most commonly affected. Cardiovascular diseases contribute to most of the sudden natural deaths of which Coronary artery disease is the leading cause. Increased awareness with regular health checkups is needed among the population at risk so as to improve quality of life.
\end{abstract}

Keywords: Sudden natural deaths, Medico-legal autopsy, Cardio-vascular system.

\section{Introduction}

World Health Organization (WHO) defines sudden death as "death within 24 hours from the onset of the symptoms". It can also be defined as deaths which are sudden, unexpected, clinically unexplained, or otherwise obscure even though there needs to be no unnatural element in their causation. ${ }^{1}$ Apurba Nandy defined Sudden death as a death which is not known to have been caused by any trauma, poisoning or violent asphyxia, and where death occurs all of a sudden or within 24 hours of the onset of the terminal symptoms. ${ }^{2}$ It is worth mentioning that emphasis is given to the unexpected character, rather than suddenness of death. The incidence of Sudden death is approximately 10 percent of all deaths where diseases of Cardiovascular system account for about $45-50 \%$, Respiratory system $15-23 \%$, Nervous system $10-18 \%$, Alimentary system 6-8\%, Genito-urinary system $3-5 \%$ and $5-10 \%$ are of miscellaneous causes. ${ }^{3}$

Sudden deaths in apparently healthy persons might raise doubt of foul play. ${ }^{4}$ Hence medico-legal autopsy is necessary in such cases to satisfy the aggrieved relatives and it also gives a systemic view of various causes of deaths in such cases which ultimately improve mortality statistics. So an attempt is made to know the statistics of sudden natural deaths occurring in rural region of Marathwada in Maharashtra.

\section{Aim and Objectives}

1. To find the socio-demographic profile of sudden natural death cases.
2. To know the various causes of sudden natural deaths.

\section{Material and Methods}

This study is a retrospective analysis of sudden natural death cases which were brought for medicolegal autopsy at Department of Forensic Medicine, Swami Ramanand Teerth Rural Govt. Medical College \& Hospital, Ambajogai, Dist. Beed, Maharashtra. The duration of the study was from 1st September 2015 to 31st August 2018. Inclusion criteria-Cases of Sudden natural deaths as per WHO definition Exclusion criteria- Unnatural deaths, natural deaths after 24 hours of hospitalization, decomposed cases.

Pro-forma for study was prepared and various information and findings were collected like age, sex, and cause of death. Clinical diagnosis was considered from medical records in hospitalized deaths. Histopathological examination report of tissues was also taken into account. Additional information was derived from police investigation report. The information was compiled, tabulated and analyzed statistically.

\section{Observation and Results}

1. During the study period from 1st September 2015 to 31st August 2018, total 1355 autopsies were conducted, out of which 217 cases (16.01\%) were of sudden natural deaths. (Table 1)

2. Sudden natural deaths occurred at any age and the youngest case was of a newborn of one hour old 
and the oldest case was of age 95 years. The most affected age group in this study was between $41-50$ years i.e. 50 cases $(23.04 \%)$, followed by $31-40$ years i.e. 44 cases $(20.28 \%)$. (Chart 1$)$

3. There was predominance of males with 168 cases $(77.42 \%)$ and 49 cases $(22.58 \%)$ were females. Male: Female ratio was 3.42:1. (Chart 2)

4. Out of the 217 cases of sudden natural deaths, in 115 cases $(53 \%)$ the cause of death was related with the cardiovascular system (CVS), in 73 cases $(33.64 \%)$ the cause of death was related with the respiratory system (RS), in 11 cases $(5.07 \%)$ the cause of death was related with the central nervous system (CNS), in 13 cases $(5.99 \%)$ the cause of death was related with the gastrointestinal system (GIT), in 3 cases $(1.38 \%)$ the cause of death was related with the urinary system (US) and in 2 cases $(0.92 \%)$ the cause of death was related with some other system. (Chart 3)

5. Out of the 115 cases of sudden natural deaths due to the cardiovascular system, in 102 cases $(88.70 \%)$ the cause of death was Coronary Artery Disease, in 7 cases $(6.09 \%)$ the cause of death was
Myocardial Infarction, in 3 cases $(2.61 \%)$ the cause of death was Myocarditis, in 2 cases $(1.74 \%)$ the cause of death was Rupture of Aortic Aneurysm and in one case $(0.87 \%)$ the cause of death was Cardiomyopathy. (Table 5)

6. Out of the 73 cases of sudden natural deaths due to the respiratory system, in 28 cases $(38.36 \%)$ the cause of death was Lobar Pneumonia, in 21 cases $(28.77 \%)$ the cause of death was Acute Pulmonary oedema, in 11 cases $(15.07 \%)$ the cause of death was pulmonary Tuberculosis, in 9 cases $(12.33 \%)$ the cause of death was Bronchopneumonia, in 3 cases $(4.11 \%)$ the cause of death was Lung Abscess and in one case $(1.37 \%)$ the cause of death was Pulmonary haemorrhage. (Table 6)

7. Intra-cerebral Haemorrhage was noted in 11 cases, Ruptured Oesophageal Varices was present in 9 cases, perforation peritonitis was noted in 3 cases, and Pyonephrosis was present in 3 cases. Acute Pancreatitis, Leukaemia and Congenital Diaphragmatic Hernia were noted in one case each. (Table 7)

Table 1: Total Number post-mortem examinations and number of sudden natural death cases during the study period

\begin{tabular}{|l|c|c|c|}
\hline Study Duration & $\begin{array}{c}\text { Total No. of } \\
\text { PME }\end{array}$ & $\begin{array}{c}\text { No. of Sudden } \\
\text { natural death } \\
\text { cases }\end{array}$ & Percentage \\
\hline $\begin{array}{l}\text { September 2015 } \\
\text { to August 2018 }\end{array}$ & 1355 & 217 & 16.01 \\
\hline
\end{tabular}

Chart 1: Age wise distribution of sudden natural death cases

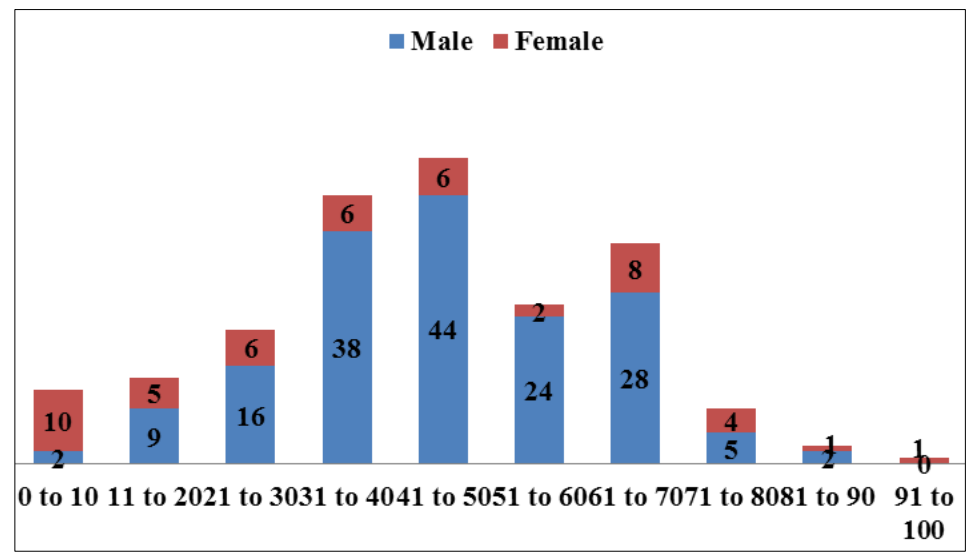


Chart 2: Sex wise distribution of sudden natural death cases

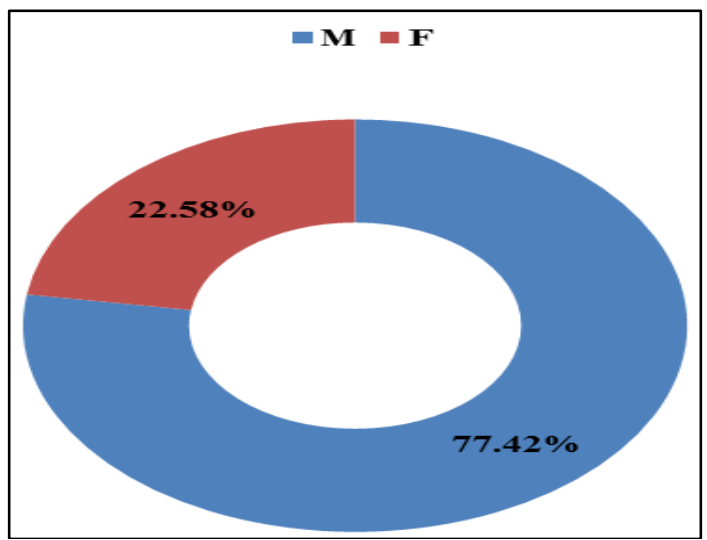

Table 2: Age and Sex wise distribution of sudden natural death cases $(\mathbf{n}=217)$

\begin{tabular}{|l|c|c|c|c|}
\hline Age $($ in years) & Male & Female & Total & Percentage \\
\hline 0 to 10 & 2 & 10 & 12 & 5.53 \\
\hline 11 to 20 & 9 & 5 & 14 & 6.45 \\
\hline 21 to 30 & 16 & 6 & 22 & 10.14 \\
\hline 31 to 40 & 38 & 6 & 44 & 20.28 \\
\hline 41 to 50 & 44 & 6 & 50 & 23.04 \\
\hline 51 to 60 & 24 & 2 & 26 & 11.98 \\
\hline 61 to 70 & 28 & 8 & 36 & 16.59 \\
\hline 71 to 80 & 5 & 4 & 9 & 4.15 \\
\hline 81 to 90 & 2 & 1 & 3 & 1.38 \\
\hline 91 to 100 & 0 & 1 & 1 & 0.46 \\
\hline Total & 168 & 49 & 217 & 100.00 \\
\hline
\end{tabular}

Table 3: Body System wise distribution of sudden natural death cases in males and females $(n=217)$

\begin{tabular}{|l|c|c|c|c|}
\hline Body System & Male & Female & Total & Percentage \\
\hline CVS & 96 & 19 & 115 & 53.00 \\
\hline RS & 49 & 24 & 73 & 33.64 \\
\hline CNS & 7 & 4 & 11 & 5.07 \\
\hline GIT & 12 & 1 & 13 & 5.99 \\
\hline US & 3 & 0 & 3 & 1.38 \\
\hline Misc. & 1 & 1 & 2 & 0.92 \\
\hline Total & 168 & 49 & 217 & 100.00 \\
\hline
\end{tabular}

Chart 3: Body System wise distribution of sudden natural death cases

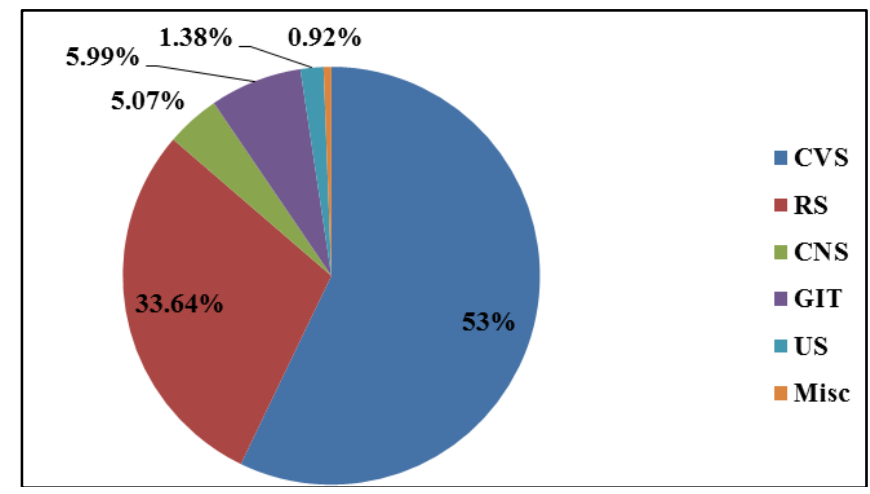


Table 4: Age and Body System wise distribution of sudden natural death cases $(n=217)$

\begin{tabular}{|l|c|c|c|c|c|c|c|c|}
\hline $\begin{array}{c}\text { Age } \\
\text { (in years) }\end{array}$ & \multicolumn{7}{|c|}{ Body System } \\
\hline 0 to 10 & 1 & 10 & 0 & 0 & 0 & 1 & 12 & 5.53 \\
\hline 11 to 20 & 2 & 10 & 0 & 0 & 2 & 0 & 14 & 6.45 \\
\hline 21 to 30 & 8 & 12 & 0 & 1 & 0 & 1 & 22 & 10.14 \\
\hline 31 to 40 & 26 & 13 & 0 & 5 & 0 & 0 & 44 & 20.28 \\
\hline 41 to 50 & 33 & 8 & 6 & 3 & 0 & 0 & 50 & 23.04 \\
\hline 51 to 60 & 13 & 7 & 4 & 1 & 1 & 0 & 26 & 11.98 \\
\hline 61 to 70 & 24 & 8 & 1 & 3 & 0 & 0 & 36 & 16.59 \\
\hline 71 to 80 & 5 & 4 & 0 & 0 & 0 & 0 & 9 & 4.15 \\
\hline 81 to 90 & 2 & 1 & 0 & 0 & 0 & 0 & 3 & 1.38 \\
\hline 91 to 100 & 1 & 0 & 0 & 0 & 0 & 0 & 1 & 0.46 \\
\hline Total & 115 & 73 & 11 & 13 & 3 & 2 & 217 & 100.00 \\
\hline
\end{tabular}

Table 5: Cardiac causes of sudden natural deaths ( $n=115)$

\begin{tabular}{|l|c|c|c|c|}
\hline Cardiac cause & Male & Female & Total & Percentage \\
\hline Coronary Artery Disease & 86 & 16 & 102 & 88.70 \\
\hline Myocardial Infarction & 6 & 1 & 7 & 6.09 \\
\hline Ruptured Aortic Aneurysm & 1 & 1 & 2 & 1.74 \\
\hline Cardiomyopathy & 1 & 0 & 1 & 0.87 \\
\hline Myocarditis & 2 & 1 & 3 & 2.61 \\
\hline Total & 96 & 19 & 115 & 100.00 \\
\hline
\end{tabular}

Table 6: Respiratory causes of sudden natural deaths $(n=73)$

\begin{tabular}{|l|c|c|c|c|}
\hline \multicolumn{1}{|c|}{ Respiratory cause } & Male & Female & Total & Percentage \\
\hline Bronchopneuminia & 2 & 7 & 9 & 12.33 \\
\hline Lobar Pneumonia & 20 & 8 & 28 & 38.36 \\
\hline Pulmonary Tuberculosis & 10 & 1 & 11 & 15.07 \\
\hline Acute Pulmonary Edema & 14 & 7 & 21 & 28.77 \\
\hline Lung Abscess & 3 & 0 & 3 & 4.11 \\
\hline Pulmonary Haemorrhage & 0 & 1 & 1 & 1.37 \\
\hline Total & 49 & 24 & 73 & 100.00 \\
\hline
\end{tabular}

Table 7: Other causes of sudden natural deaths

\begin{tabular}{|l|l|c|c|c|}
\hline $\begin{array}{c}\text { Involved Body } \\
\text { System }\end{array}$ & \multicolumn{1}{|c|}{ Cause } & Male & Female & Total \\
\hline CNS & Intra-cerebral Haemorrhage & 7 & 4 & 11 \\
\hline \multirow{3}{*}{ II System } & Acute Pancreatitis & 1 & 0 & 1 \\
\cline { 2 - 5 } & Ruptured Oesophageal Varices & 9 & 0 & 9 \\
\cline { 2 - 5 } & Perforation Peritonitis & 2 & 1 & 3 \\
\hline Urinary System & Pyonephrosis & 3 & 0 & 3 \\
\hline Blood dyscrasias & Leukaemia & 1 & 0 & 1 \\
\hline Congenital defect & Congenital Diaphragmatic Hernia & 0 & 1 & 1 \\
\hline
\end{tabular}

\section{Discussion}

1. In the present study, the incidence of sudden death was $16.01 \%$ amongst all the medico-legal autopsies conducted during the study period. Similar incidence was found in the study conducted by Ambade V.N. (15.48\%)..$^{5}$ The incidence of sudden natural deaths in the present study is inconsistent with the studies conducted by Meina Singh A. $(2.66 \%)^{6}$, Pandian J.R. $(8.61 \%){ }^{7}$ Zanjad N.P. $(8.92 \%)^{8}$ and Azmak A.D. (28.98\%). ${ }^{9}$
This inconsistency might be due to the differences in selection of cases due to the difference of opinions in the definition of sudden natural death.

2. We observed that in the present study there is a predominance of males with 168 cases $(77.42 \%)$ than females with 49 cases $(22.58 \%)$ and the Male: Female ratio was 3.42:1. Consistent results with respect to male population were noted by Thomas A.C.

$(73.9 \%)^{10}$, Ambade V.N. $(79.27 \%)^{5}$, Nordrum I. $(79.67 \%)^{11}$, Sarkioja T. $(82 \%)^{12}$, Azmak A.D. 
$(83.4 \%)^{9}$, Zanjad N.P. $(84.8 \%)^{8}$, Pandian J.R. $(86.66 \%)^{7}$, Dayananda R. $(86.76 \%)^{13}$ and Meina Singh A. $(94.5 \%)^{6}$

3. We observed that in the present study the most affected age group is between $41-50$ years i.e. 50 cases $(23.04 \%)$ followed by $31-40$ years i.e. 44 cases $(20.28 \%)$. Similar findings were noted by Pandian J.R. ${ }^{7}$ where $31.67 \%$ cases belonged to 41 50 years age group and $28.33 \%$ cases belonged to 31-40 years age group. Similar results where 41-50 years age group contributed to highest cases was found in the studies conducted by Ambade $\mathrm{V} \mathrm{N}$. $(20 \%)^{5}$, Chaudhari S.H. $(30.81 \%)^{14}$ and Meina Sing A. (34.5\%). ${ }^{6}$ Zanjad N.P. ${ }^{8}$ observed similar findings where $31-50$ years age group contributed to $52.66 \%$ cases. Dayananda R. ${ }^{13}$ observed that $64.70 \%$ cases were from $25-50$ years age group. Doolan A. ${ }^{15}$ noted maximum case in the age group 31-35 years.

4. Out of the 217 cases of sudden natural deaths the diseases of cardiovascular system were found in 115 cases $(53 \%)$. Similar findings were noted by Chaudhari S.H. $(44.6 \%),{ }^{14}$ Siboni A. $(46.2 \%),{ }^{16}$ Kuller L. $(49.5 \%)^{17}$, Zanjad N.P. $(49.55 \%)^{8}$, Azmak A.D. $(55 \%)^{9}$, Pandian J.R. $(55.83 \%){ }^{7}$ Di Maio Vincent JM (60.9\%), ${ }^{18}$ Sarkioja T. $(61 \%),{ }^{12}$ Dayananda R. (62.74\%), ${ }^{13}$ Nordrum I. (69.15\%). ${ }^{11}$ Our results are also comparable with the study conducted by Farb A. ${ }^{19}$ and revealed that sudden natural deaths are most commonly due to cardiac diseases and most common in males.

5. Out of the 115 cases of sudden natural deaths due to the cardiovascular system, in 102 cases (88.70\%) the cause of death was Coronary Artery Disease. Similar findings were noted by Dayananda R. (92.96\%), ${ }^{13}$ Zanjad N.P. (86.47\%), ${ }^{8}$ Chaudhari S.H. $(76.05 \%)^{14}$. Consistent results were also noted in the studies conducted by Kuller L. ${ }^{17}$, Di Maio Vincent JM, ${ }^{18}$ Luke J.L. ${ }^{20}$ Nordrum I., ${ }^{11}$ Sarkioja T., ${ }^{12}$ Siboni A., ${ }^{16}$ Meina Sing A. ${ }^{6}$ Ambade V.N. ${ }^{5}$ and Thomas A.C. ${ }^{10}$

6. Myocardial Infarction was noted in $6.09 \%$ cases. Near similar results were noted in the studies conducted by Dayananda R. $(3.12 \%)^{13}$ and Chaudhari S.H. $(14.08 \%)^{14}$

7. Myocarditis was found in three cases. Pandian J.R. ${ }^{7}$ found two cases, Yogesh Prasad Sah ${ }^{21}$ found two cases and Zanjad N.P. ${ }^{8}$ found one case of myocarditis.

8. Ruptured Aortic Aneurysm was present in 2 cases. Dayananda R. ${ }^{13}$ also found two cases of Ruptured Aortic Aneurysm.

9. Cardiomyopathy was found in one case. Zanjad N.P. ${ }^{8}$ found three cases, Pandian J.R. ${ }^{7}$ found four cases, Chaudhari S.H. ${ }^{14}$ found one case and Yogesh Prasad $\mathrm{Sah}^{21}$ also found one case of Cardiomyopathy.
10. Out of the 217 cases of sudden natural deaths in 73 cases $(33.64 \%)$ the cause of death was related with the respiratory system. Similar findings were noted by Zanjad N.P. (27.23\%), ${ }^{8}$ Chaudhari S.H. $(25.78 \%),{ }^{14}$ Dayananda R. $(22.55 \%)^{13}$ and Pandian J.R. (16.67\%). ${ }^{7}$ The main causes were pneumonia and tuberculosis. This was comparable with the study done by Bobrowitz ID ${ }^{22}$, Zanjad N.P., ${ }^{8}$ Chaudhari S.H. ${ }^{14}$ Pandian J.R., ${ }^{7}$ Dayananda R. ${ }^{13}$ and Yogesh Prasad Sah. ${ }^{21}$ The principal acute complications of tuberculosis were hemoptysis and pneumothorax.

11. Intra-cerebral Haemorrhage was noted in 11 cases. Intra-cerebral Haemorrhage was also found in the studies conducted by Pandian J.R. (4 cases) ${ }^{7}$ Zanjad N.P.(4 cases) ${ }^{8}$ Dayananda R. $(2 \text { cases })^{13}$ and Chaudhari S.H. (2 cases). ${ }^{14}$

\section{Conclusion}

1. The incidence of sudden natural death is $16.01 \%$.

2. Sudden natural death has male predominance with age group 41-50 years followed by 31-40 years.

3. Maximum cases has Cardiovascular causes (53\%) followed by Respiratory causes (33.64\%).

4. Coronary artery disease is the main cause of cardiovascular deaths and also of tops among all causes of sudden natural deaths.

5. Histopathological examination helps in determining the cause of death.

6. Increased awareness is needed among the population at risk. Regular health checkups may diagnose the disease or risk factors like hypertension, dyslipidaemia earlier and so quality of remaining life can be improved and it may also decrease the number of sudden natural deaths.

7. We recommend the health care providers especially emergency physicians to pay attention to patients presenting with prodromal symptoms.

\section{Conflict of Interest: None}

Source of funding: None

\section{References}

1. WHO International Classification of Diseases and related health problems 10th revision (ICD 10) version for 2010. Available from:

who.int/classifications/icd10/browse/2010/en\#R96.

Accessed on 2015 Dec 5

2. Nandy A. Principles of Forensic Medicine including Toxicology, 3rd Ed, New Central Book Agency (P) Ltd: Kolkata, 2010:226-229.

3. Reddy KSN, Murty OP. Death and its cause. The Essentials of Forensic Medicine and Toxicology. $33^{\text {rd }}$ ed.: Jaypee Brothers Medical publishers (P) Ltd, New Delhi; 2014: p150

4. Parikh CK. Parikh's Textbook of Medical Jurisprudence, Forensic Medicine and Toxicology. 5th Ed. New Delhi: CBS Publishers and Distributors; 2005: 254.

5. Ambade V. N. Study of natural deaths in Nagpur Region. $\mathrm{J}$ Medicolegal Association of Maharashtra. 2002;14(2):11-4. 
6. Meina Singh A, Subadani Devi S, Nabachandra H, Fimate L. Sudden death in Manipur - A preliminary study. J Forensic Med Toxicol 2002;19(2):26-8.

7. Pandian JR, Laishram RS, Kumar LD, Phuritsabam P, Debnath K. Autopsy review of sudden deaths in a tertiary hospital of north-eastern India. J Med Soc 2014;28:145-8.

8. Zanjad NP, Nanandkar SD. Study of sudden unexpected deaths in medico-legal autopsies. J Indian Acad Forensic Med 2006;28(1):27-30.

9. Azmak A.D. Sudden natural deaths in Edirne, Turkey from 1984 to 2005. Med Sci Law 2007; 47(2): 147-55.

10. Thomas A.C, Knapman PA, Krikler DM, Davis MJ. Community study of the causes of "Natural" sudden death. Br Med J 1988;297(3):1453-56.

11. Nordrum I, Eide TJ, Jorgensen L. Unexplained and explained natural deaths among persons above one year of age in a series of medico-legal autopsies. Forensic Sci Int 1998; 93:89-98.

12. Sarkioja T, Hirvonen J. Causes of sudden unexpected deaths in young and middle aged persons. Forensic Sci Int 1984;24:247-61.

13. Dayananda R, Priyadarshee Pradhan, Kumar M P. Pattern of Sudden Natural Deaths among Autopsies Conducted at Mysore Medical College. J Indian Acad Forensic Med 2018;40(2):146-50.

14. Chaudhari S.H., Anand Mugadlimath, Mandar Sane, K.U. Zine, D.I. Ingale, Rekha Hiremath. Study of Sudden Natural Deaths in Medico-Legal Autopsies with Special Reference to Cardiac Causes. Int J Cur Res Rev 2013;5(3):37-42.

15. Doolan A, Langlois N, Semsarian C. Causes of sudden cardiac death in young Australians. Med J Aust 2004;180:110-12.

16. Siboni A, Simonsen J. Sudden unexpected natural death in young persons. Forensic Sci Int 1986; 31:159-66.

17. Kuller L, Lilienfeld A, Fisher R. Sudden and unexpected deaths in young adults. JAMA1966;198(3):248-52.

18. Di Maio Vincent JM, Di Maio Dominick JM. Natural death as viewed by the medical examiner. A Review of 1000 consecutive autopsies of individuals dying of natural disease. J Forensic Sci 1991;36(1):17-24.

19. Farb A, Tang AL, Burke AP, Sessums L, Liang Y, Virmani R. Sudden coronary death. Frequency of active coronary lesions, inactive coronary lesions, and myocardial infarction. Circulation 1995;92:1701-9.

20. Luke JL, Helpern M. Sudden unexpected death from natural causes in young adults. Arch Pathol 1968;85:106.

21. Yogesh Prasad Sah. Sudden Natural Deaths in Medicolegal Cases-An Autopsy Based Study. IOSR J Dent Med Sci (IOSR-JDMS) 16.12(2017):42-5.

22. Bobrowitz ID. Active tuberculosis undiagnosed until autopsy. Am J Med 1982;72:650-58. 